Esteban Bravo Botta. Claudia Ramírez Krause. Karin Saavedra Ramírez

\title{
Análisis de la cuestión de inconstitucionalidad, a partir de la sentencia del tribunal constitucional rol $N^{\circ} 681-2006$
}

\section{Analysis of the question of unconstitutional from the judgment of the Constitutional Court role $N^{\circ} 681-2006$.}

\begin{abstract}
Resumen
El presente trabajo expone la cuestión de inconstitucionalidad, a partir del análisis de la sentencia del Tribunal Constitucional recaída en el artículo 116 del Código Tributario, el cual permitía a los Directores del Servicio de Impuestos Internos delegar en un funcionario la función jurisdiccional que legalmente les correspondía. Es así como se exponen los antecedentes del caso y el marco legal aplicable, para luego profundizar en la argumentación de los principales considerandos del referido fallo, con especial énfasis en los principios invocados, sus efectos y los problemas jurídicos derivados de este, haciendo referencia a las soluciones existentes en derecho comparado y la potestad administrativa sancionadora, para finalizar con algunas ideas a modo de conclusiones.
\end{abstract}

\section{Palabras Claves}

Juez tributario, función jurisdiccional, recurso de inconstitucionalidad

*Abogados.

Investigadores de la

Unidad de Pedagogía

Universitaria y

Didáctica del Derecho,

Facultad de Derecho, Universidad de Chile.

\begin{abstract}
This paper presents the question of unconstitutionality, from the analysis of the Constitutional Court ruling handed down in Article 116 of the Tax Code, which allowed the directors of the Internal Revenue Service an official delegate to the judicial function that legally belonged. This is how, we present a previous history of the case and the applicable legal framework, and then delve into the arguments of the main paragraphs of that judgment, with special emphasis on the principles invoked, its effects and legal problems arising from it, referring existing solutions in comparative law and the administrative authority to impose penalties, to end with some ideas by way of conclusion
\end{abstract}

Keywords

Tax judge, adjudicatory jurisdiction, appeal of unconstitutionality 


\section{Análisis de la cuestión de inconstitucionalidad sentencia rol $\mathrm{N}^{\circ}$ 681-2006}

\section{A.- Antecedentes}

El Código Tributario contemplaba una serie de procedimientos cuyo conocimiento estaba radicado en la Administración, representada por el Servicio de Impuestos Internos ${ }^{1}$. Esta potestad fue altamente criticada en doctrina por sus semejanzas con el antiguo sistema procesal penal: procedimiento secreto; juez inquisitivo (el Director Regional del Servicio de Impuestos Internos no se desprendía de su calidad de funcionario público dependiente) y falta de imparcialidad, entre otros ${ }^{2}$. En este contexto, en 1994, en el marco del procedimiento de reclamación general y de denuncias por infracción de las normas tributarias, por aplicación de los artículos $6^{\circ}$ letra b) número 6 y 115 y siguientes del Código Tributario, el Servicio de Impuestos Internos mediante una Resolución determinó que era posible delegar en el Jefe del Departamento Jurídico de cada Dirección Regional la facultad contenida en el art. 115 del Código Tributario, esto es, "conocer en primera o única instancia, según proceda, de las reclamaciones deducidas por los contribuyentes y de las denuncias por infracción a las disposiciones tributarias (...)". Dicha delegación tiene como fuente normativa el artículo 116 del mismo cuerpo dispositivo, el cual preceptuaba "El Director Regional podrá autorizar a funcionarios del Servicio para conocer y fallar reclamaciones y denuncias obrando por orden del Director Regional" 3 .

Las contradicciones prácticas que esta delegación producía en el juicio tributario, básicamente se traducían en que el funcionario que presentaba las liquidaciones de impuesto que eran sujeto de reclamación, era muchas veces dependiente de la misma Dirección Regional que tenía que conocer de la reclamación ${ }^{4}$. Sobre esta materia, la doctrina era partidaria de aplicar el recurso de inaplicabilidad por inconstitucionalidad, como mecanismo de protección de las garantías constitucionales 5 . Es por ello que existe una variada jurisprudencia, por ejemplo Sentencias de Excelentísima CS Roles No $3.419-2001$ y $2.536-2003^{6}$.

\footnotetext{
Así, por ejemplo, encontramos los siguientes procedimientos:

a) El procedimiento general de reclamaciones (art. 123 a 148);

b) El procedimiento general de aplicación de sanciones (art. 161);

c) El procedimiento especial para aplicación de ciertas multas (art. 165);

d) El procedimiento de aplicación de sanciones que merecen pena corporal (art. 162 a 163);

e) El procedimiento de cobro ejecutivo de las obligaciones tributarias de dinero (art. 168 a 199).

MORALES (1999), p. $53-76$.

Esta norma es reproducida en el art. 29 de la Ley Orgánica del Servicio de Impuestos Internos, el cual contenía la misma facultad delegatoria.

MORALES (1999), p. 64.

FIGUEROA (1987), p. 68

Un caso interesante que ejemplifica el control constitucional en concreto en materia tributaria que realizan los Tribunales Constitucionales, es el recurso de inaplicabilidad por inconstitucionalidad interpuesto por la Compañía
} 
Solo por citar un ejemplo del criterio establecido por los tribunales superiores de justicia, la CA de Santiago, en "Molinera Heredia S.A. con Servicio de Impuestos Internos", declaró que la delegación que han hecho de sus funciones jurisdiccionales los Directores Regionales de Impuestos Internos es improcedente, por lo que las sentencias dictadas por los llamados "Jueces Tributarios" lo han sido por autoridades administrativas que carecen de jurisdicción, vicio que influye sustancialmente en la marcha del juicio y en lo dispositivo del fallo, razón por la cual debe anularse, en consecuencia, todo lo obrado 7 .

En el caso de la sentencia Rol 681-2006, la Corte Constitucional cita las siguientes sentencias de inaplicabilidad: Roles No 478, 499, 502, 515, 520, 525, 526, 527, 528, $547,554,555,566,569,574,595,604,605,606,613,614,627,628,629,630$, 635, 636, 639, 640, 641, 642, 647, 657 y 658, todos del 2006.

\section{B.- Facultad de declaración de oficio por parte del Tribunal Constitucional}

En el caso en estudio, estamos en presencia de una excepción a la regla general de pasividad de la función jurisdiccional, pues el artículo $93 \mathrm{~N}^{\circ} 7$ y artículo $93 \mathrm{~N}^{\circ} 7$ inciso $12^{\circ}$ de la Constitución permiten al Tribunal Constitucional actuar de oficio; de este modo, puede expulsar del ordenamiento jurídico una norma legal que se encuentre en contradicción con la Carta Fundamental, cuestión que sucede en la sentencia que analizaremos ${ }^{8}$. Dicha facultad, según lo manifestado por el propio Tribunal Constitucional en Sentencia Rol No 558-2006, es una potestad que el legislador constituyente le entrega a este órgano controlador en términos facultativos y no perentorios ${ }^{9}$, además de ser deseable su utilización, por la conveniencia de expulsar normas contrarias a la Constitución, así como al interés social que esto contempla (Considerando $4^{\circ}$ Sentencia Rol 681-2006) ${ }^{10}$.

de Teléfonos de Chile S.A. en contra de la Ilustre Municipalidad de Villa Alemana, por un cobro de ocupación de la vía pública con mantención de escombros y materiales de construcción y remoción de pavimentos, por el cual, por aplicación del art. 43 del Decreto Ley №3.063 sobre Rentas Municipales, se cursó un cobro equivalente al 78,4\% del valor del proyecto de ampliación que se estaba realizado. La Corte Suprema determinó que la aplicación del precepto citado resultaba contrario a los arts. 19 № 20, 60 № 2 y 14, 62 inciso 4 № 1, $6^{\circ}$ y $7^{\circ}$, todos de la Constitución, dado que permiten a una autoridad la fijación libre y a su arbitrio de tributos. Sentencia de 28 de Enero de 1992, contenida en Revista de Derecho y Jurisprudencia y Gaceta de los Tribunales, Tomo LXXXIX, No 1, (Enero-Abril), Sección 5, Editorial Jurídica de Chile, Santiago, Chile, 1992, citado por IBACETA y MEZA (2005), pp. 242-245.

7 RDJ, Tomo XCVII, No 2 (Mayo-Agosto), Sección Segunda, Editorial Jurídica de Chile, Santiago, Chile, año 2000, citada por IBACETA y MEZA (2005), ídem.

8 El tribunal parte la sentencia, pronunciándose sobre su facultad de actuar de oficio, así, declara tener en consideración las cuatro primeras sentencias de inconstitucionalidad del art. 116 del CT, luego constató que se cumplieran los presupuestos exigidos por el art. 93 , inciso $1^{\circ} \mathrm{N}^{\circ} 7$ e inciso $12^{\circ}$ de la Constitución.

9 “(...) la atribución del TC derivó de un deber a una facultad, lo que conforma el texto final aprobado, que le otorgó la potestad de resolver soberanamente la inconstitucionalidad de un precepto legal previamente declarada inaplicable. (...), el TC ejercita su atribución facultativamente y no se encuentra obligado a efectuar una declaración de inconstitucionalidad"Considerandos $16^{\circ}$ y $17^{\circ}$.

10 Ver Rol 1345-09-Inc, en la que actuando también de oficio, el TC se pronunció sobre la inconstitucionalidad del art. 171 del Código Sanitario. En este caso, previamente se había declarado inaplicable este precepto en las Sentencias Roles 792, 1071, 1049, 1253, 1262 y 1279, del 2009. 
B.1. Presupuestos constitucionales y procesales necesarios para la declaración de inconstitucionalidad de un precepto legal.

\section{B.1.1. Marco Jurídico aplicable}

En la sentencia son utilizadas las siguientes normas como fuente para resolver la cuestión de inconstitucionalidad: artículo $5^{\circ}, 6^{\circ}, 7^{\circ}, 19$ o 3 , inciso cuarto, 38, inciso segundo, 64, 76, 77 y 93, inciso primero, numeral $7^{\circ}$, e inciso duodécimo, de la Constitución Política de la República, artículo 30 y 31 de la Ley No 17.997, Orgánica Constitucional del Tribunal Constitucional y principios jurídicos de Derecho Público que ya expondremos.

B.1.2. Presupuestos necesarios para declarar la inconstitucionalidad de una determinada norma legal

a) Debe tratarse de un precepto de rango legal;

b) La referida norma debe haber sido declarada previamente inaplicable por sentencia de este Tribunal pronunciada en virtud de lo dispuesto en el artículo 93, inciso primero del numeral 6º y artículo 93 inciso undécimo de la Constitución;

c) El proceso de inconstitucionalidad debe haberse iniciado por el ejercicio de una acción pública acogida a tramitación por la Corte Constitucional o por una resolución del mismo actuando de oficio, $y$

d) Abrirse proceso sustanciándose y dictándose la correspondiente sentencia.

B.1.3. Principios constitucionales envueltos en la declaración de nulidad de una norma

Interesante es la utilización de principios jurídicos como criterios relevantes que utiliza el Tribunal Constitucional en esta sentencia; de hecho los denomina "principios cardinales del derecho público" (Considerando $26^{\circ}$ ), identificados los siguientes principios: supremacía constitucional, (artículo 6 y 7 Constitución Política de la República), concentración de la justicia constitucional, igualdad ante la ley (artículo $19 \mathrm{n}^{\circ} 3$ de la Carta Fundamental) y, de certeza jurídica. Como se puede observar, en esta construcción argumental la Corte Constitucional no solo recurre a principios expresamente consagrados en la Constitución, sino que además construye sus propios principios constitucionales, como el de certeza jurídica (Considerando $8^{\circ}$ ).

\section{C.- Traslado a los órganos interesados}

Haciendo uso de la facultad conferida en el artículo 33 A de su Ley Orgánica Constitucional, el Tribunal Constitucional ofició a los órganos constitucionales que estimó 
interesados en este proceso, con la finalidad de poner en conocimiento del examen de constitucionalidad respecto del artículo 116 del Código Tributario, con la finalidad de que emitieran su opinión.

Así, se dispuso poner en conocimiento de: su Excelencia Presidenta de la República; Honorable Senado; Honorable Cámara de Diputados ${ }^{11}$; Servicio de Impuestos Internos, y el Consejo de Defensa del Estado. De dichos órganos solo respondió el Servicio de Impuestos Internos informando que enmendó jurídicamente la delegación al dejarlas sin efecto mediante Resolución Exenta № 118, del año 2006.

\section{D.- Control abstracto de constitucionalidad del art. 116 del Código Tributario}

En el momento de analizar un precepto constitucional en términos abstractos, el Tribunal Constitucional debe hacerlo teniendo en cuenta la presunción de la constitucionalidad del acto del legislativo, de forma que el precepto impugnado pueda resultar armonioso con la Constitución. Lo anterior por cuanto, de los artículos 6 y 7 de la Constitución Política de la República, todos los órganos de la Administración del Estado, sin distinción, deben someter su acción a la Constitución y a las normas dictadas conforme a ella. Este mandato, conocido como la "regla de clausura del Derecho Público", incluso abarca la tramitación de las leyes y demás cuerpos normativos que realizan tanto el Poder Legislativo como el Ejecutivo, inclusive a la Excma. Corte Suprema mediante Autos Acordados. Ergo, si el principio de supremacía constitucional obliga a los órganos que tienen atribuciones de creación normativa en nuestro ordenamiento $^{12}$, eso quiere decir que se habrían excedido en sus potestades si dictaran normas contrarias a la Carta Fundamental.

Es por tal motivo que el propio Tribunal Constitucional, en su función de contralor de la constitucionalidad de la ley, debe buscar, al menos, alguna interpretación del precepto cuestionado que permita armonizarlo con la Carta Fundamental y solo en el evento de no ser ello posible, unido a la necesidad de cautelar integralmente la plena vigencia del principio de supremacía constitucional, resultará procedente y necesaria la declaración de inconstitucionalidad ${ }^{13} \mathrm{y}^{14}$

11 Llama la atención que ninguno de los órganos legislativos y el Ejecutivo como impulsor de la actividad normativa respondieran el traslado señalado, en especial consideración a que estaba en tramitación el Proyecto de reforma "Fortalecimiento y Perfeccionamiento de la justicia tributaria y aduanera". Ver historia de la ley $\mathrm{N}^{\circ} 20.322$, páginas 951 a 990, disponible en http://www.bcn.cl/histley/lfs/hdl-20322/HL20322.pdf [consulta: 03 de Julio de 2011].

12 VIVANCO (2001), pp. 393-396.

13 La CS actuando como TC en sentencia de 15.04.97. señaló que aceptar que mediante la declaración de inconstitucionalidad de un decreto se enjuicie implícitamente el contenido de una ley, importaría vulnerar gravemente el art. 82 de la Carta Fundamental, por cuanto, no autoriza al TC a emitir juicios implícitos o explícitos sobre la constitucionalidad de una norma legal, cita de MONTT (1997), p. 67.

14 Considerando $8^{\circ}$, sentencia 681-2006. Este razonamiento también lo utilizó en sentencias Roles 309, 409 y $558(590)$. 
En esta búsqueda la Corte Constitucional Chilena confrontó el artículo 116 del Código Tributario con los siguientes artículos de la Constitución: $5^{\circ}$ inciso $1^{\circ}$, relativo a jurisdicción como atributo de la soberanía; artículo $6^{\circ}$ que contiene el principio de supremacía constitucional; artículo $7^{\circ}$ sobre la competencia de los órganos públicos; artículo 19 № 3 inciso $4^{\circ}$, relativo a las comisiones especiales; artículo 38 inciso $2^{\circ}$, sobre reclamación de los particulares afectados en sus derechos por actuaciones cometidas por un órgano de la Administración; artículo 76 inciso $1^{\circ}$, el cual trata sobre la facultad jurisdiccional entregada al Poder Judicial; artículo 76 inciso $2^{\circ}$, que consagra el principio de inexcusabilidad y artículo 77 sobre delegación normativa a una Ley Orgánica Constitucional para la organización y determinación de atribuciones de los tribunales de justicia.

Sin embargo, adelantando una conclusión, el examen realizado por el Tribunal Constitucional resulta forzado ya que, en nuestra opinión, el tema a discutir era el debido proceso en la justicia tributaria, vale decir, la confrontación del artículo 116 del Código Tributario con el artículo 19 No 3 inciso $5^{\circ}$ de la Constitución.

\section{E. Argumentos para fallar la inconstitucionalidad del art. 116 del Código Tributario}

\section{E.1. Derecho Administrativo Sancionador:}

El Tribunal Constitucional ha tenido distintas oportunidades para referirse a lo que en doctrina se denomina "Derecho Administrativo Sancionador". Así, con ocasión del requerimiento de inaplicabilidad, Rol 479-2006, la Corte Constitucional declaró que en el ejercicio de las facultades punitivas de la administración, se imponen conductas tanto para esta, como imponer sanciones, como para los administrados, como ejercer atribuciones, sanciones que deben estar graduadas dependiendo de la naturaleza infraccional ${ }^{15}$. De este modo, a la potestad sancionadora de la administración también le resulta aplicable el principio de legalidad ${ }^{16}$.

\section{E. 2. Naturaleza jurisdiccional del juez tributario}

De los términos utilizados por el artículo 38 inciso $2^{\circ}$ de la Constitución se desprende que existirán tribunales encargados de revisar los conflictos de carácter litigioso que surjan con ocasión del ejercicio de las potestades públicas entre la administración y los administrados. La Constitución, en esta materia, solo se limita a señalar la existencia de estos tribunales, pero es el artículo $4^{\circ}$ del Código Orgánico de Tribunales el que prescribe que pueden existir tribunales especiales que no se encuentren dentro de la

Considerando $5^{\circ}$.

Considerando $6^{\circ}$, donde reitera la jurisprudencia contenida en sentencia Rol 480-2006. 
organización del Poder Judicial, vale decir, una norma de rango legal. De este modo, reconoce la sentencia de que los Tribunales Administrativos en materia tributaria no pertenecen al Poder Judicial, sino que forman parte de la Administración, por lo que se vinculan con el Poder Ejecutivo.

En este contexto, la autorización que confiere dicho órgano, en virtud del cuestionado artículo 116 del Código Tributario, en su calidad de juez tributario a funcionarios de su dependencia, implica una delegación del ejercicio de la jurisdicción, toda vez que dice relación con el conocimiento y fallo de reclamaciones y denuncias tributarias que le ha otorgado la ley, en forma privativa, a dicha autoridad a través del artículo 115 del mismo cuerpo legal.

$\mathrm{Al}$ respecto, el Tribunal Constitucional ha afirmado la naturaleza jurisdiccional de la facultad entregada al Director Regional del Servicio de Impuestos Internos, en virtud de los siguientes argumentos:

a.- Pronunciamientos de inaplicabilidad que sirven de antecedente y fundamento a esta sentencia, incluyendo los preceptos constitucionales que regulan el ejercicio de la jurisdicción y su distribución entre los tribunales establecidos por la ley ${ }^{17}$. En este sentido, tiene en consideración que la Constitución entrega al legislador orgánico la labor de determinación de organización y atribución de los tribunales.

b.- Historia fidedigna del establecimiento de las respectivas disposiciones legales

c.- Precisiones conceptuales efectuadas por el propio Servicio de Impuestos Internos, a través del informe que hace presente al Tribunal Constitucional ${ }^{18}$;

d.- Antecedentes del proyecto de ley sobre tribunales tributarios, en trámite legislativo $^{19}, \mathrm{y}$

e.- Correlación armónica de diversos preceptos contenidos en el mismo Código Tributario.

La Corte Constitucional Chilena, haciéndose cargo de aquellos que argumentaban que la delegación es administrativa, enmarcada dentro del artículo 41 de la Ley $\mathrm{N}^{\circ}$ $18.575^{20}$, Orgánica Constitucional de Bases Generales de la Administración del Estado, señala que no se dan los presupuestos contenidos en dicha norma, porque esta delegación administrativa es siempre parcial; sin embargo, lo que ha realizado el Servicio de Impuestos Internos es una delegación total de su facultad de resolver los procedimientos sometidos a su conocimiento.

$17 \mathrm{Al}$ respecto ver sentencia $\mathrm{Rol} \mathrm{N}^{\circ}$ 17.7167, de 1992

18 Como se señaló previamente el Servicio de Impuestos Internos informó que, sobre esta materia, ejercía facultades jurisdiccionales.

19 En dicho trámite legislativo la CS informó que, por aplicación del art. $5^{\circ}$ inciso cuarte del COT, el Juez Tributario forma parte de los tribunales especiales. Al respecto ver historia fidedigna de la ley $\mathrm{N}^{\circ} 20.322$, páginas $437-441$ en http://www.bcn.cl/histley/lfs/hdl-20322/HL20322.pdf [consulta: 03 de Julio de 2011].

20 Ver dictamen $\mathrm{N}^{\circ} 18.359$, de 05.05 .57 , de la Contraloría General de la República. 
Sobre estos argumentos resuelve que la atribución en comento es de naturaleza jurisdiccional y no administrativa, lo cual conlleva importantes consecuencias para la institucionalidad tributaria, especialmente por la aplicación de las garantías que tienen los contribuyentes en este procedimiento.

\section{E.3. Principios cardinales del Derecho Público enunciados por el Tribunal Constitucional}

La Corte Constitucional nacional, en este fallo, fue enfática en señalar que siendo la jurisdicción un atributo de la soberanía, era indelegable por aquellos a quienes se les había conferido. Razón por la cual el artículo 116 del Código Tributario, al facultar al Director Regional del Servicio de Impuestos Internos para delegar la facultad jurisdiccional que le ha confiado el legislador, vulneraría abiertamente el artículo $5^{\circ}$ inc. $1^{\circ}$, en tanto en cuanto consagra el principio de Soberanía, en relación con el artículo 76 inciso $1^{\circ}$ de la Constitución.

Por otra parte, el Tribunal se refiere a la infracción del art. 76 inciso $2^{\circ}$ de la Constitución, referente al deber de inexcusabilidad, en cuanto a que el Director Regional del Servicio de Impuestos Internos, al delegar sus funciones en otro funcionario, estaría evadiendo el cumplimiento de sus funciones jurisdiccionales.

Además, el Tribunal Constitucional considera que el aludido artículo 116 del Código Tributario, al permitir la delegación de facultades jurisdiccionales, vulnera los principios de separación de poderes y de legalidad, consagrados en los artículos $6^{\circ}$ y $7^{\circ}$ de la Constitución Política de la República; aún más, enfatiza que se ha transgredido en su esencia el principio de legalidad, ya que no se estaría cumpliendo con los requisitos indispensables para desarrollar actuaciones válidas ante el derecho. Siguiendo esta línea argumental, el tribunal que resuelva conflictos tributarios debe ser creado y mandatado por la propia ley; el hecho de que la norma cuestionada permitiera delegar las facultades jurisdiccionales a través de una Resolución Exenta en un funcionario público cualquiera, que no tiene el carácter de juez, no se ajusta a la forma prescrita por la propia Constitución para designar a sus jueces razón por la cual se transformaría en un juez ad-hoc o en una comisión especial, argumento con el que el fallo cuestiona el cumplimiento del principio de juez natural, principio por el cual una persona solo puede ser juzgada por el tribunal que señale la ley previamente constituido ${ }^{21}$.

21 El Tribunal Constitucional construye el principio de juez natural interpretando los arts. $19 \mathrm{~N}^{\circ} 3$ inc. $4^{\circ}$, art. 38 , inc. 2 , art. 76 inc. $1^{\circ}$, art. 77 inc. $2^{\circ}$, art. $1^{\circ}$ inc. $4^{\circ}$ y art. $5^{\circ}$ inc. $2^{\circ}$, todos de la Carta Fundamental (Considerandos $15^{\circ}$ y $25^{\circ}$. Llama la atención que el mencionado Tribunal para construir este principio, hace referencia a los mismos artículos para crear el principio de seguridad jurídica. 


\section{E. 4. Principio de seguridad jurídica: (principio construido)}

Una de las cuestiones que llaman la atención en el fallo en comento es que no solo lo resuelve basado en argumentos de texto constitucional, sino que también se basa en los principios que ya fueron expuestos. Como se ha advertido, algunos de ellos tienen pleno fundamento de texto, pero otros carecen de él.

Esto es lo que sucede con el principio de seguridad o certeza jurídica, el cual, en opinión del Tribunal Constitucional, se desprende de los artículos $1^{\circ}$ inc. $4^{\circ}$ y artículo $5^{\circ}$ inc. $2^{\circ}$ de la Constitución Política de la República, no obstante ocupar argumentos que parecen más propios del análisis del desarrollo de la garantía constitucional de un procedimiento y una investigación racional y justa ${ }^{22}$ De este modo, se automandata a dar cumplimiento a este principio, por la importancia que este tiene en nuestro Estado de Derecho ${ }^{23}$.

\section{Efectos y consecuencias de la declaración de insconstitucionalidad del artículo 116 del Código Tributario}

1) En cuanto a sus efectos, el fallo en su considerandos $7^{\circ}$ y $9^{\circ}$ señala que la facultad de declarar inconstitucional un precepto legal importa eliminar una norma del ordenamiento jurídico vigente, reforzándose con ello el Estado de Derecho, razón por la cual, consecuencialmente, se fortalece el sistema de separación de poderes y se garantiza la protección de los principios constitucionales de supremacía constitucional y legalidad. Además, transcribe los efectos de la declaración de inconstitucionalidad según el texto constitucional, entendiéndose el precepto derogado a contar de la fecha de su publicación en el Diario Oficial, que debe ocurrir 3 días después de dictada la sentencia respectiva, además de mencionar que esta no es retroactiva.

Así, a la fecha de la derogación del mencionado artículo 116, ocurrida el 9 de marzo del 2007, existían procesos pendientes tanto en el Tribunal Constitucional como en la justicia ordinaria que involucraban dicha normativa derogada. En la Corte Constitucional se tramitaban acciones de inaplicabilidad del artículo 116, pero ante su derogación, este Tribunal resolvió no acogerlas porque el precepto impugnado había sido derogado, y declarar su inaplicabilidad en esas condiciones implicaría dotar a la inaplicabilidad de efecto retroactivo.

Pero persistía el problema de qué hacer con los procesos pendientes, sobre todo generado porque las actuaciones del Juez Tributario se habían producido al inicio del proceso y, en esa fecha, aún estaba vigente el art. 116 del Código en comento. Por otra parte, dicha norma no es de "aplicación eventual en un juicio", sino que es una

22 El Tribunal en su considerando $25^{\circ}$ señala que resulta fundamental para la seguridad jurídica que una persona sea juzgada por un tribunal previamente constituido y, en un procedimiento que cumpla con los estándares constitucionales.

23 Considerando $25^{\circ}$. 
norma decisoria litis. Frente a estos casos, la Corte Suprema de Justicia decidió declarar la nulidad de todo lo obrado, desde la intervención del Juez Tributario - Delegado, en virtud de lo establecido en el artículo 83 inciso 1 y artículo 84 inciso final del Código de Procedimiento Civil. La Corte arribó a esta solución basándose en que estos procesos, en su origen, carecían de un tribunal que ejerciera la jurisdicción de manera legítima, ya que el artículo 116 del Código Tributario, como norma habilitante para ejercer la jurisdicción, había sido declarado inconstitucional.

2) Otra de las consecuencias de este fallo dice relación con la tramitación del proyecto de ley que fortalece y perfecciona la jurisdicción tributaria y aduanera. Este proyecto de ley, en sus inicios, si bien reconocía la necesidad de contar con tribunales tributarios especializados e imparciales, proponía una estructura que aún seguía vinculada al Servicio de Impuestos Internos, ya que la planta y el escalafón de los nuevos Jueces Tributarios estaban dentro del mencionado Servicio. Esto generó suspicacias en varios sectores del país, ya en el año 2002, cuando se presentó este proyecto de ley, la Excma. Corte Suprema, en su fallo de 20 de febrero de 2002, objetó esta posición, acogiendo la inaplicabilidad del artículo 116, señalando que si los Directores Regionales del Servicio de Impuestos Internos no poseen independencia e imparcialidad para resolver las reclamaciones de contribuyentes ni tienen inamovilidad en sus cargos, no cumplen con las normas constitucionales sobre funcionamiento de los tribunales ${ }^{24}$

Finalmente, el Congreso decide aprobar el proyecto de ley separando definitivamente a los Jueces Tributarios del SII, aunque manteniendo su funcionamiento administrativo en manos de Ministerio de Hacienda, el mismo Ministerio del cual depende el Servicio de Impuestos Internos.

\section{Comentarios y reflexiones sobre el fallo}

\section{A.- Problemas juRÍdicos derivados de la deRogación DEL ART. 116 DEL Código TRIBUTARIO}

En cuanto a los efectos de la declaración de inconstitucionalidad de un precepto legal, se aprecia la escasa densidad normativa para resolver los enormes problemas jurídicos que provoca, contenida tanto en la Constitución como en la Ley Orgánica del Tribunal Constitucional. En este caso, se trataba de una norma que al ser declarada inconstitucional generó dificultades jurídicas, originadas principalmente por la anulación de los procesos pendientes y su retroceso al estado de tramitación anterior a la intervención del juez tributario - delegado, perjudicando con ello tanto a los contribuyentes como

\footnotetext{
Historia de la Ley No 20.322, página 411, disponible en http://www.bcn.cl/histley/lfs/hdl-20322/HL20322. $p d f$ [consulta: 03 de Julio de 2011].
} 
al fisco. Resumidamente se puede señalar que el fisco vio afectados sus intereses económicos, ya que al retrotraerse los procesos, estos debían reiniciarse en su tramitación con los mismos valores nominales originales, y, a su vez, los contribuyentes, luego de años de tramitación legal, continuaron con sus reclamaciones tributarias sin resolver, sin mencionar que ahora debían sustanciarlas ante el Director Regional del Servicio de Impuestos Internos actuando como Juez Tributario, adoleciendo del mismo vicio de imparcialidad ya mencionado.

Al consultar la legislación comparada en casos de derogación de normas por sentencias del Tribunal Constitucional, nos encontramos con soluciones en las cuales sus Constituciones, y regulaciones propias de los Tribunales Constitucionales, dan respuesta al asunto.

1) El Código Procesal Constitucional Peruano, si bien señala que la sentencia que declara la inconstitucionalidad de un precepto legal tiene efectos erga omnes e irretroactivos, igualmente dota al Tribunal Constitucional de facultades especiales a la hora de declarar la inconstitucionalidad en materias tributarias ${ }^{25} \mathrm{~A}$ su vez, el mismo Tribunal debe determinar de manera expresa, en la sentencia, los efectos de su decisión en el tiempo, y resolver lo pertinente respecto de las situaciones jurídicas producidas mientras estuvo en vigencia ${ }^{26}$.

2) La ley del Tribunal Constitucional Español parte de la base del efecto erga ommes e irretroactividad de las sentencias de procedimientos de inconstitucionalidad y otorga a dicho Tribunal la facultad de declarar la nulidad de los preceptos impugnados, así como, en su caso, la de aquellas otras disposiciones legales o reglamentarias en las que deba extenderse por conexión o consecuencia. Además, excepcionalmente, puede revisar procesos terminados en los cuales se haya aplicado la disposición declarada inconstitucional solo si se trata de procesos penales o contencioso-administrativos referentes a un procedimiento sancionador en que, como consecuencia de la nulidad

25 Art. 74 de la Constitución Peruana: Principio de Legalidad Los tributos se crean, modifican o derogan, o se establece una exoneración, exclusivamente por ley o decreto legislativo en caso de delegación de facultades, salvo los aranceles y tasas, los cuales se regulan mediante decreto supremo./ Los Gobiernos Regionales y los Gobiernos Locales pueden crear, modificar y suprimir contribuciones y tasas, o exonerar de éstas, dentro de su jurisdicción, y con los límites que señala la ley. El Estado, al ejercer la potestad tributaria, debe respetar los principios de reserva de la ley, y los de igualdad y respeto de los derechos fundamentales de la persona./ Ningún tributo puede tener carácter confiscatorio./ Las leyes de presupuesto y los decretos de urgencia no pueden contener normas sobre materia tributaria. Las leyes relativas a tributos de periodicidad anual rigen a partir del primero de enero del año siguiente a su promulgación.

No surten efecto las normas tributarias dictadas en violación de lo que establece el presente artículo.

26 Art. 81 del Código Procesal Constitucional: Efectos de la Sentencia fundada Las sentencias fundadas recaídas en el proceso de inconstitucionalidad dejan sin efecto las normas sobre las cuales se pronuncian. Tienen alcances generales y carecen de efectos retroactivos./ Cuando se declare la inconstitucionalidad de normas tributarias por violación del artículo 74 de la Constitución, el Tribunal debe determinar de manera expresa en la sentencia los efectos de su decisión en el tiempo. Asimismo, resuelve lo pertinente respecto de las situaciones jurídicas producidas mientras estuvo en vigencia.

Art. 83. del Código Procesal Constitucional: Efectos de la irretroactividad Las sentencias declaratorias de ilegalidad o inconstitucionalidad no conceden derecho a reabrir procesos concluidos en los que se hayan aplicado las normas declaradas inconstitucionales, salvo en las materias previstas en el segundo párrafo del artículo 103 y último párrafo del artículo 74 de la Constitución. 
de la norma aplicada, resulte una reducción de la pena o de la sanción o una exclusión, exención o limitación de la responsabilidad ${ }^{27}$.

Lo anterior nos lleva a concluir que en estos casos de declaración de inconstitucionalidad de una norma, sobre todo las que versan sobre ciertas materias (penales, contenciosoadministrativas y decisoria litis), el efecto derogatorio no es suficiente para responder los nuevos problemas jurídicos que conlleva, sino que es necesario que el legislador se haga cargo de las consecuencias jurídicas de la expulsión del ordenamiento jurídico de una norma de rango legal.

En virtud de esto, estimamos necesario que en casos de sentencias de este tipo, el Tribunal Constitucional notifique al Legislador y al Ejecutivo para promover la deliberación pública sobre aquella norma declarada inconstitucional.

\section{B. Debido Proceso en el antiguo Juicio Tributario}

En nuestra opinión, la sentencia en estudio no se pronunció sobre la conciliación entre las normas procesales en materia tributaria y el artículo 19 o 3 , inciso $5^{\circ}$ de la Constitución Política de la República, vale decir, el debido proceso en la justicia tributaria, el cual era el gran cuestionamiento a esta judicatura, dado que, en nuestro criterio, en el momento de la dictación de la sentencia sobre la inconstitucionalidad del artículo 116 del Código Tributario, ya estaba en conocimiento la Corte Constitucional de que había sido declarado admisible un requerimiento de inaplicabilidad de los artículos 6, letra B) № 6, y artículo 115 del Código Tributario y artículo 19 letra b), del DFL No 7, Ley Orgánica del Servicio de Impuestos Internos (Rol 616-2006), por ser dichas normas contrarias al artículo 19 № 3, inciso $5^{\circ}$ de la Carta Magna. Ergo, el Tribunal prefirió pronunciarse en este fallo sobre el debido proceso, y dejar para el control abstracto del artículo 116 del Código Tributario el problema de la naturaleza jurídica del Juez Tributario.

27 Art. 35 de la Ley Orgánica del Tribunal Constitucional Espańol: Cuando un Juez o Tribunal, de oficio o a instancia de parte, considere que una norma con rango de Ley aplicable al caso y de cuya validez dependa el fallo pueda ser contraria a la Constitución, planteará la cuestión al Tribunal Constitucional con sujeción a lo dispuesto en esta Ley.

Art. 38 de la Ley Orgánica del Tribunal Constitucional Español: Las sentencias recaídas en procedimientos de inconstitucionalidad tendrán el valor de cosa juzgada, vincularán a todos los poderes y producen efectos desde su publicación en el boletín oficial del estado.

Art. 39 de la Ley Orgánica del Tribunal Constitucional Español: Cuando la sentencia declare la inconstitucionalidad, declarará igualmente la nulidad de los preceptos impugnados, así como, en su caso, la de aquellos otros de la misma ley, disposición o acto con fuerza de ley, a los que deba extenderse por conexión o consecuencia.

Art. 40 de la Ley Orgánica del Tribunal Constitucional Español: Las sentencias declaratorias de la inconstitucionalidad de Leyes, disposiciones o actos con fuerza de Ley no permitirán revisar procesos fenecidos mediante sentencia con fuerza de cosa juzgada en los que se haya hecho aplicación de las Leyes, disposiciones o actos inconstitucionales, salvo en el caso de los procesos penales o contencioso-administrativos referentes a un procedimiento sancionador en que, como consecuencia de la nulidad de la norma aplicada, resulte una reducción de la pena o de la sanción o una exclusión, exención o limitación de la responsabilidad. 
De este modo, la sentencia Rol 616-2006 rechaza la inaplicabilidad por considerar que "se resguardan los principios fundamentales minimos que deben informar un proceso justo y racional, en los términos que ordena el art 19 No 3 de la Constitución Política de la República, previéndose mecanismos eficaces y eficientes que permiten que tribunales superiores revisen lo obrado y resuelto en primera instancia por el órgano jurisdiccional respectivo, encontrándose este último sujeto en todo evento a la superintendencia disciplinaria de la Corte Suprema de Justicia" (Considerando 40).

Lo anterior no quiere decir que en dicha sentencia el mencionado Tribunal no se pronunciara sobre la naturaleza jurídica del Juez Tributario, sino que, por el contrario, se explaya latamente sobre la materia, como ocurre con los Considerandos $16^{\circ}$ a $18^{\circ}$, $23^{\circ}, 24^{\circ}$ y $28^{\circ}$, pero lo hace sobre la base de dilucidar el cumplimiento de ser este procedimiento un procedimiento racional y justo.

\section{C.- Potestad administrativa sancionadora}

Doctrinariamente la constitucionalidad de esta potestad ha sido cuestionada ${ }^{28}$; $\sin$ embargo, el Tribunal Constitucional, en sentencia Rol 681-2006, ratifica su doctrina anterior y reconoce constitucionalidad a la facultad de la Administración para resolver conflictos jurisdiccionales. Así, concluye que el Director Regional, funcionario dependiente del Servicio de Impuestos Internos, ergo, del Poder Ejecutivo, ejerce facultades jurisdiccionales al conocer y resolver reclamaciones deducidas por los contribuyentes y las denuncias por infracción a las disposiciones tributarias ${ }^{29}$. De este modo, el Tribunal Constitucional zanja la discusión doctrinaria, reconociendo que la administración puede ejercer facultades jurisdiccionales ${ }^{30}$.

28 Sin entrar en detalle, se puede resumir que en este debate existen dos posturas:

a) Inconstitucionalidad de la Potestad Administrativa Sancionadora: Esta potestad es considerada ilegítima por asimilarla a una potestad jurisdiccional, que involucra una acción de juzgar un "delito", aunque sea administrativo, por ende, por aplicación del art. 76 de la CPR esta facultad le está entregada exclusivamente al Poder Judicial, negando a otro poder del Estado la facultad de ejercer funciones jurisdiccionales. En todo caso cabe señalar que esta es la tesis minoritaria. (Planteamiento sostenido por Aróstica Maldonado y Soto Kloss) y; b) Constitucionalidad de la Potestad Administrativa Sancionara: Se reconoce legitimidad pero se trasvasijan los principios del Derecho Penal, con ciertos matices, de modo de no negar la autonomía del Derecho Administrativo en su especialidad sancionadora. Así, los principios que se trasvasijan son: legalidad, reserva legal y tipicidad. (Planteamiento sostenido por Camacho Zepeda, Pantoja Bauzá, Vergara Blanco, Parada Vásquez, entre otros, y por el propio TC en Sentencias Roles Nos. 479-2006, 478-2006).

Al respecto Ver Camacho Z., Gladys, "La legitimidad de la Potestad Administrativa Sancionadora”, Revista de Derecho Público, Universidad de Chile, Facultad de Derecho, Tomo II, Volumen No 69, 2007, páginas 9 a 23.

29 En Considerando $17^{\circ}$ el Tribunal Constitucional señala que el art.77 de la Constitución Política de la República entregó al legislador orgánico la determinación de organización y atribución de los tribunales que fueren necesarios para la pronta y cumplida administración de justicia en todo el país, y es en este contexto, donde el Código Tributario reviste a los Directores Regionales del SII, por aplicación del art. 115 del mismo cuerpo dispositivo, de facultades jurisdiccionales; situación que se ratifica con lo dispuesto en el art. 120 del citado Código, cuando entrega a las Corte de Apelaciones respectivas, la revisión en segunda instancia de los recursos de apelación deducidos contra sus resoluciones.

30 Ver considerandos $19^{\circ}$ y $20^{\circ}$. 
Resolver esta cuestión no fue fácil en el seno de la Corte Constituciona ${ }^{31}$; $\sin _{\text {embargo, }}$ pronunciarse al respecto resultaba trascendental para el asunto sometido a su conocimiento, dado que determinar la constitucionalidad o no de la delegación de la facultad conferida al Director Regional del Servicio de Impuestos Internos, en el artículo 115 del Código Tributario, pasaba primero por determinar la naturaleza de esta facultad.

En nuestra opinión, el razonamiento utilizado por la mencionada Corte Constitucional es acertado, dado que conlleva el trasvasije de los principios del Derecho Penal, con matices, al procedimiento tributario, como forma de concreción del Estado de Derecho $^{32}$. Así, se pueden identificar las siguientes consecuencias:

a) Las sanciones deben estar expresamente descritas y establecidas por la ley y no en un reglamento.

b) El contenido de la sanción debe tener su contenido esencial descrito por la norma legal ${ }^{33}$.

c) El procedimiento debe garantizar las normas del debido proceso, esto es: imparcialidad de quien decide, un procedimiento establecido por la ley, debido emplazamiento, derecho a defensa, y que las sanciones no se apliquen con efecto retroactivo.

\section{Conclusiones}

Los efectos, que al ejercer la facultad del art. $93 \mathrm{~N}^{\circ} 7$ de la Constitución Política de la República, particularizados en el fallo en comento, no conllevan sólo nuevos desafíos jurídicos, sino también tienen implicancias políticas, económicas e, inclusive, sociales, dependiendo de las materias en las que pueda llegar a ser utilizada.

Nosotros solo abordamos el análisis del fallo y algunas de sus consecuencias a partir del alcance de la facultad derogatoria del Tribunal Constitucional, y es así como hemos explicitado que la mencionada Corte Constitucional, al resolver conflictos constitucionales, no lo hace solo en el empleo de la norma cuestionada, sino también en la confrontación de dicha norma con principios constitucionales expresamente consagrados en la Constitución y otros construidos por él. Solo en esta lógica es posible entender la frase de los "principios cardinales de Derecho Público" y proceder a darles aplicación en sede de inconstitucionalidad, dentro del control abstracto de la norma.

31 Los Ministros Jorge Correa Sutil y Mario Fernández Fredes, estuvieron por rechazar la inconstitucionalidad por estimar que este procedimiento es de índole administrativa y no jurisdiccional; mismo criterio que utilizaron posteriormente en la Sentencia Rol 616-2006, donde, contrario a lo resuelto por la mayoría de los Ministros del Tribunal Constitucional, estuvieron por declarar la inaplicabilidad de los art. $6^{\circ}$, letra B), № 6 y 115 del Código Tributario y el art. 19, letra b) del Decreto con Fuerza de Ley No 7, de 1980, Ley Orgánica del Servicio de Impuestos Internos, por estimarlos vulneratorios al art. 19 № 3, inciso $5^{\circ}$ de la Constitución Política de la República.

$32 \operatorname{VILLAR}(1999)$, p. 87.

33 Así lo ha resuelto el Tribunal Constitucional en Sentencia Rol 468-2006, sobre la inaplicabilidad del art. 299 No 3, del Código de Justicia Militar. 
Es necesario destacar el enorme potencial hermenéutico que pueden adquirir estos principios al resolver cualquier tipo de conflicto constitucional producido en nuestro ordenamiento, aunque es necesario debatir cómo operan estos principios, al tiempo que encontramos citadas las mismas normas para el principio del juez natural y de seguridad jurídica (artículos $1^{\circ}$ inciso $4^{\circ}$ y artículo 5 inciso $2^{\circ}$ Carta Fundamental).

En nuestra opinión, el hecho de construir principios sin fundamento de texto atenta contra la seguridad jurídica que pretende proteger, así como el uso de términos comunes en doctrina, que empleados de forma distinta determinan una atenuación de la norma positiva del texto constitucional. Esto en el sentido de que se asientan principios, evolucionan, mutan de significados y las normas que efectivamente les dan sustento a ellos permanecen casi inalteradas de lo escrito por los constituyentes originarios.

Si bien nos parece adecuada la resolución del Tribunal Constitucional y un enorme avance, en cuanto a que ella permite, al definir la naturaleza jurisdiccional de la facultad en comento, dar aplicación a las garantías que todo ciudadano tiene ante un órgano jurisdiccional, opinamos que pudo haber arribado a dicha conclusión por una vía diversa: argumentando sobre la base del debido proceso.

Qué distinta hubiese sido la sentencia si hubiera abordado el problema señalando cuándo estamos en presencia de un proceso jurisdiccional y, consecuentemente, cuándo este proceso puede ser estimado como debido; cuáles son las garantías mínimas que contiene el debido proceso al amparo de nuestra normativa constitucional y si estas están satisfechas en el procedimiento que se seguía ante el juez tributario. En todo caso, comprendemos que la tarea de abordar la garantía del debido proceso, la hace en relación del recurso de inaplicabilidad interpuesto en contra del artículo 115 del Código Tributario, que estaba pendiente de ser evacuado por el Tribunal Constitucional. Al menos, tenemos conciencia de la consistencia de su jurisprudencia, al comparar el presente fallo con lo resuelto en el fallo antes indicado, pues se reúnen las mismas mayorías y minorías en relación a la distinción si lo que hay en juego es una atribución de naturaleza administrativa o jurisdiccional.

Otro aspecto interesante es la falta de densidad normativa en la regulación de los efectos de declaración de inconstitucionalidad, ya que, en este caso, la Excma. Corte Suprema, mediante la declaración de nulidad, se hizo cargo de dar solución a los procesos pendientes que estaba conociendo, lo que, sin embargo, causó más perjuicios que beneficios. Tenemos la certeza de que este tema es y será objeto de nutridos estudios dentro de la doctrina, por su complejidad y por las múltiples alternativas de soluciones a las que legítimamente se puede arribar.

Por último, es destacable la importancia dogmática de este fallo y la necesidad de su difusión y estudio, pues nos parece relevante para estudiar las razones y motivaciones en razón de cómo decide el Tribunal Constitucional y cómo puede resultar derogada una norma jurídica construida democráticamente. 


\section{Bibliografía}

\section{Fuentes bibliográficas}

HORMAZABAL MALARÉE, Hernán. 2008. El Nuevo Tribunal Constitucional, Los Derechos Fundamentales y El Moderno Recurso de Inaplicabilidad. Santiago de Chile, editorial Legal Publishing. 2a Edición.

VILLAR ESCURRA., José luis, "Derecho Administrativo Especial. Administración Pública y Actividad de los Particulares", editorial Civitas, Madrid, año 1999.

VIVANCO M., Ángela, "Curso de Derecho Constitucional. Bases conceptuales y doctrinarias del Derecho Constitucional”, Tomo I, Textos Universitarios, Facultad de Derecho, Ediciones Universidad Católica de Chile, año 2001.

ZÚÑIGA URBINA, Francisco (Coordinador). Año 2005. Reformas Constitucional. Santiago de Chile, editorial Lexis Nexis.

ZÚNIIGA URBINA, Francisco. Acciones de Inaplicabilidad e Inconstitucionalidad. Santiago de Chile, editorial Abeledo Perrot Legal Publishing, año 2010.

\section{Fuentes hemerográficas}

CAMACHO CEPEDA, Gladys. 2007. La Legitimidad de la Potestad Administrativa Sancionadora. Revista de Derecho Público de la Universidad de Chile, volumen $\mathrm{N}^{\circ} 69$.

CEA EGAÑA, José Luis. 2008. Efectos de la declaración de inconstitucionalidad. Dificultades y desafíos. Revista Actualidad Jurídica de la Universidad del Desarrollo, $\mathrm{N}^{\circ} 17$.

IBACETA MEDINA, David. Meza Encina, Bárbara. 2005. Mecanismos de Control de principio Constitucional de Legalidad Tributaria. Dos Casos Constitucionales, un Caso Legal. Revista de Derecho Público de la Universidad de Chile, volumen $\mathrm{N}^{\circ} 67$.

MONTT OYARZÚN, Santiago, "El Recurso de Inaplicabilidad por Inconstitucionalidad, ¿Es Garantía Suficiente de un Sistema Tributario Justo?. Revista Derecho y Humanidades, No 7, 1997.

MORALES ROBLES, Eduardo, "La "Justicia" Tributaria". Revista de Derecho de la Universidad Finis Terrae. Facultad de Derecho, Universidad Finis Terrae. Año III, No 3, 1999. 
Fuentes Bibliográficas En Línea:

1. HISTORIA DE LA LEY No 20.322, que Fortalece y Perfecciona la Justicia Tributaria y Aduanera, en http://www.bcn.cl/histley/lfs/hdl-20322/HL20322.pdf.

2. LEY No 28.237 QUE CONTIENE EL CÓDIGO PROCESAL CONSTITUCIONAL PERUANO, en www.tribunalconstitucional.pe.

3. LEY ORGÁNICA 2/1979, del Tribunal Constitucional Español, Texto consolidado e integrado con las modificaciones introducidas por las Leyes Orgánicas 8/1984, 4/1985, 6/1988, 7/1999 y 1/2000 y las reformas conforme a las Leyes Orgánicas 6/2007, de 24 de mayo, y 1/2010, de 19 de febrero, en www.tribunalconstitucional.es.

4. SENTENCIAS DEL TRIBUNAL CONSTITUCIONAL. ROLES 478-2006, 479-2006, 480-2006, 558-2006, 616-2006, 681-226, 3.396-2006, 1.243-2008, 3.145-2009 INC, en www.tribunalconstitucional.cl.

5. SENTENCIAS DE LA CORTE SUPREMA ROLES 3.419-2001, 189-2007, 264-2007, en www.poderjudicial.cl. 